\title{
Banging the same old colonial drum? Moving from individualising practices and cultural appropriation to the ethical application of alternative practices in social work
}

Canice Curtis and Christine Morley School of Public Health and Social Work, Queensland University of Technology

\begin{abstract}
INTRODUCTION: Western conceptualisations of social work are increasingly interested in practices considered to be alternative or non-traditional to respond to oppression. While incorporating alternative methods into social work is frequently viewed as unproblematic, we suggest critical reflection is necessary to safeguard against inadvertent, culturally unsafe practice and the uncritical re-inscription of individualised solutions.

APPROACH: In this article, we explore the application of group drumming practices within social work through examination of a critical incident. While the benefits of group drumming are well documented, we use critical reflection to explore ethical challenges of incorporating group drumming practices into social work.

CONCLUSIONS: We highlight strategies for social workers using alternative or nontraditional practices that support cultural humility and critical practice goals. This research holds implications for social workers interested in the potential of alternative practices while remaining committed to critical practice and cultural safety.
\end{abstract}

KEYWORDS: Critical social work; critical reflection; group drumming; cultural safety

Social work has adopted primarily Western ways of working (Chenoweth \& McAuliffe, 2015; Healy, 2014). Within contemporary contexts dominated by neoliberalism and managerialism is the ascendance of particular modes of practice including individual therapies, case management, behaviour modification techniques, and risk assessment (Payne, 2014; Chenoweth \& McAuliffe, 2015). In the last decade, there has been emerging interest in alternative methods. For example, there is currently research into using equine therapies in social work interventions (Acri, Hoagwood, Morrissey, \& Zhang, 2016; Burgon, Gammage, \& Hebden, 2017), incorporating yoga into social work (Behrman \& Tebb, 2009; Mahaffey, 2016) and the benefits of mindfulness and meditation (Bo, Mao, \& Lindsey, 2016; Garland, 2013; Winters \& Beerbower, 2017). While poststructuralism celebrates diversification of practice, critical (modernist) theories caution about adopting approaches that potentially individualise structural problems, and reproduce and/ or impose colonialism. This article focuses
AOTEAROA

NEW ZEALAND SOCIAL WORK 31(2), 29-41.

CORRESPONDENCE TO: Christine Morley c3.morley@qut.edu.au 
on another alternative practice: group drumming in the tradition of djembe drumming (Bittman et al., 2001; Fancourt et al., 2016; Faulkner, Wood, Ivery, \& Donovan, 2012; Ho, Tsao, Bloch, \& Zeltzer, 2011) to consider the cultural and ethical issues raised by critical perspectives, including how structural concerns can be redefined as personal pathologies, and how uncritical applications of group drumming can lead to culturally unsafe practices such as cultural appropriation. Using critical reflection to examine a particular practice incident (Fook, 2016), we ultimately suggest ways to incorporate group drumming practices into social work that support critical practice.

\section{Background to the study}

\section{Djembe drumming and social work}

Djembe is a drum originally from West Africa and associated with creation myths and the intertwined histories of West African tribes and societies (Charry, 1996; Flaig, 2010). The drum is typically made from hardwood and goatskin and can produce many different sounds, making it a versatile drum suitable for playing in groups (Charry, 1996; Flaig, 2010). Sekou Toure, the first president of Guinea, has been credited with initiating the Western interest in djembe drumming (Charry, 1996; Flaig, 2010). Toure used djembe drumming styles from diverse groups within the newly founded country to create a national ballet and drumming group that led to international acclaim and interest (Charry, 1996; Flaig, 2010; Polak, 2005).

There have been numerous studies that demonstrate the effectiveness of group drumming with various population groups including: children and young people (Bittman et al., 2001; Branscombe, Chandler, \& Little, 2016; Faulkner et al., 2012; Ho et al., 2011; Skewes McFerran, 2017; Wood, Ivery, Donovan, \& Lambin, 2013); people accessing mental health services (Fancourt et al., 2016; Perkins, Ascenso, Atkins, Fancourt, \& Williamon, 2016); and war veterans
(Friedman, 2000) for example. Group drumming practices have also been trialled as a self-care strategy for social workers (see for example, Bittman et al., 2003; Bittman et al., 2004; MacMillan, Maschi, \& Tseng, 2012; Newman, Maggott, \& Alexander, 2015). While the benefits of group drumming are well documented, questions exist about the often uncritical nature of the studies.

\section{Group drumming as a social work practice with children and young people}

The literature about group drumming as a social work practice with children and young people is predicated largely on a seminal study by Bittman et al. (2001), which is entirely biomedical in focus. Saliva samples measured increases in hormones associated with positive emotions following group drumming sessions. However, there was no social analysis about how long-term illhealth is exacerbated by social determinants. While useful for measuring the physiological benefits of group drumming, the focus on the physical/organic aspects of illness, without acknowledgement of the social conditions that cause or exacerbate health- related issues, is of limited use to social work.

Building on this study, Faulkner et al. (2012) describe the DRUMBEAT (Discovering Relationship Using Music, Beliefs, Emotions, Attitudes \& Thoughts) early intervention programme devised by the West Australian drug and alcohol treatment agency, Holyoake, which uses drumming to engage young people. The programme was developed in response to the difficulties of engaging young people (particularly Aboriginal and Torres Strait Islander young people) with cognitive-behavioural therapy (CBT). All 60 students in the study were considered at increased risk of a range of negative health outcomes in later life. These histories included one or more of the following factors: social isolation, low academic performance, low self-esteem, family conflict, antisocial behaviour, sensation seeking, rebelliousness, high 
absenteeism and experimental drug use. A total of $40 \%$ of participants were Indigenous. The study ultimately reports that self-esteem, school attendance, cooperation and collaboration increased for participants and there was a decline in antisocial behaviour. Yet, both the programme and its evaluation ignore the history of percussion unique to Aboriginal and Torres Strait Islander peoples, and eschew the wider context of colonialism and oppression. Rather than dismantling oppressive structures, the programme offered drumming and CBT practices to assist young people to conform to the education system.

As a corollary, Wood et al. (2013) conducted a broader evaluation of the DRUMBEAT programme across 19 schools, indicating it provides a creative medium for at-risk young people and helps develop selfesteem and social relationship skills. Again, consideration of social factors that contribute to young people being at risk was absent from the analysis. As with the other studies, there was no acknowledgement of the cultural aspects of drumming practices with young people from diverse cultural backgrounds.

Similarly, a Californian qualitative study (Ho et al., 2011) that focused on young people, primarily of Latino descent (90\%), used teacher reports to measure the effectiveness of a school-based drumming program that was integrated with activities from group counselling. The study reported significant improvements in participants' social-emotional behaviour according to "narrow-band syndrome scales, DSMoriented scales, and other scales" (Ho et al., 2011, p. 8). However, no consideration was given to the structural dimensions of inequality and the multiple stressors that low-income families experience. Hence, the programme was simply successful in making disadvantaged children behave in more socially acceptable ways to fit into the school environment, despite growing up in a divided society. There was also no exploration of the potential for cultural appropriation, and other practices that may have already been embedded as part of the research participants' culture.

Better in this regard, Branscombe et al. (2016) made and played drums as part of the rituals and communication within the classroom to promote social cohesion. Given a number of the students were from African cultures, the authors identify the need for culturally safe practice on the part of teacher/facilitator. Skewes McFerran (2017) similarly identified the need for culturally sensitive and inclusive group facilitators who can skilfully manage power relations and cultural differences within the group. This research, however, does not consider issues of cultural appropriation and the potential for existing practices within their group's culture to be unearthed.

\section{Group drumming in the mental health field}

Group drumming literature in the mental health field is similarly dominated by psychological and biomedical discourses that individualise social problems and neglect cultural considerations. A recent study by Fancourt et al. (2016), for example, found group drumming decreased depression and anxiety in a group of mental health service users. This study's psychological and biomedical focus was indicated by its methods: standardised psychology questionnaires and collecting saliva samples.

Perkins et al. (2016) conducted qualitative, semi-structured interviews and focus groups with the same study participants as Fancourt et al. (2016) to explore specific elements of the group drumming intervention that enhanced mental health. This study found the nature of drumming as a form of non-verbal communication, and as an inclusive space free from hierarchy, was the most significant contributing factor to mental health improvements (Perkins et al., 2016). This is a valuable finding as 
these features of group drumming begin to address some of the social dimensions of people's experiences, many of whom may have difficulties communicating due to experiences of inequality and exclusion. However, the cultural appropriateness of using African drumming in the United Kingdom or other Western countries is left unexplored.

\section{Group drumming as self-care for social workers}

Group drumming has also been identified as an effective self-care practice for social workers. Some studies offer a rather narrow, psychologised view of stress, burnout and well-being (Bittman et al., 2003; Bittman et al., 2004). More contemporary studies explore drumming practice in terms of its capacity to contribute to social wellbeing (MacMillan et al., 2012; Newman et al., 2015). However, consistent with the literature on group drumming in other fields, none of the studies explore the ethics and cultural appropriateness of implementing group drumming from another culture. In addition, these studies also lack a critical analysis because they do not address why social workers might need to engage in so much self-care, thereby ignoring the harm of the neoliberal project and resulting managerial practices within social work systems and organisations.

\section{Other benefits of group drumming}

There are a handful of studies with populations deemed to be vulnerable that suggest group drumming can help (Friedman, 2000; Longhofer \& Floresch, 1993; MacIntosh, 2003; Watson, 2002; Winkelman, 2003). A consistent limitation with all of these studies is their failure to question the ethics of co-opting practice from one culture, filtering it through the lens of the social worker and imposing that practice onto a vulnerable group. Friedman (2000) collected evidence of war veterans suffering with PTSD, psychiatric rehabilitation patients, Alzheimer and Parkinson's disease patients; stroke and cancer patients, and autistic children as being aided by group drumming. Other groups reported to benefit from group drumming include people with substance abuse issues (Winkelman, 2003), adult male sex offenders (Watson, 2002), adult and adolescent trauma survivors (MacIntosh, 2003), and people diagnosed with major psychiatric illnesses such as schizophrenia (Longhofer \& Floresch, 1993). However, in each of these studies, the issues are constructed within dominant psychologised and medicalised discourses that individualise social problems and use drumming as a way of treating an assumed pathology.

As a consistent theme throughout the literature, such uncritical applications of group drumming are problematic for social work that claims to promote social justice, human rights, to challenge social barriers and promote the liberation of people (Australian Association of Social Workers [AASW], 2010; Aotearoa New Zealand Association of Social Workers [ANZASW], 2007). Indeed, Ramsden (2002), who developed the concept of cultural safety, would argue that manifestations of culturally unsafe practice, such as cultural appropriation, are more likely to emerge in the absence of the critical approaches. Consistent with critical social work, others agree that cultural safety involves addressing power dynamics, recognising the structural dimensions of people's lived experiences, valuing cultural identity, and engaging in self-critical reflection (see, for example, Frankland, Bamblett, \& Lewis, 2011). Therefore, this study will develop a critical analysis of incorporating group drumming practices into social work, with consideration of relevant cultural and ethical issues.

\section{Ethical considerations when utilising group drumming in social work}

The literature suggests adoption of group drumming to enhance social work practice offers benefits for several populations. 
However, if social work practice is to meet its espoused commitments to addressing inequality and injustice, critical analysis of the significant ethical and cultural considerations involved in incorporating group drumming into social work practice is fundamental (AASW, 2010; ANZASW, 2007).

Following explication of the underpinning theoretical framework, which is addressed next, the remainder of this article presents a critical reflection on one author's practice (Canice), using group drumming with Traveller children in Ireland. Irish Travellers are arguably the most stigmatised and disadvantaged group in Irish society (Gmelch \& Gmelch, 2014; Ó hAodha, 2011). Travellers have existed for centuries in Ireland, moving around the countryside providing trades and services (Gmelch \& Gmelch, 2014). Often confused with other Indigenous nomadic European groups, such as Roma, Travellers are native to Ireland with about 30,000 currently living there (Central Statistics Office, 2012). Discrimination has increased because of the modernisation of Ireland resulting in a decline in demand for trades and services provided by Travellers and their move to urban areas in search of work (Ó hAodha, 2011). This critical reflection examines the ethical and cultural considerations involved in adopting group drumming while working with Irish Travellers, with the intention of aligning such a practice with anti-oppressive social work ethics and values.

\section{Towards a theoretical framework to explore the use of alternative practices}

\section{Critical theories}

A number of critical theories inform this research. Modernist critical theories expose the root cause of social problems within social structures, thus challenging the location of problems with the individual. Given the emphasis on social, cultural, economic and historical conditions and contexts influencing individual and community experience (Mullaly, 2007), modernist critical theories highlight the need for social work to facilitate progressive social change, and not simply focus on practice strategies that help people adapt to injustice (Morley, 2014). Modernist critical theories also highlight white privilege. A key contribution of critical theory to this research then is the questioning of the power dynamics and ethics involved in a white Western male's appropriation of group drumming from a colonised African culture, and the application of this practice onto a cultural group: Traveller children in Ireland.

A critical form of poststructuralism also informed this research to elucidate dominant discourses, reveal unheard voices, and highlight possibilities to develop critical practices. Hence a version of critical theory that encompasses both modernist and poststructural insights was used both to critique potentially oppressive and exploitative practices retained (modernist critical perspective), and to connect the researcher with a sense of agency, to challenge social injustices, by considering diverse options for action (poststructuralism).

Poststructuralism allows recognition of the competing realities that, while engaging in group drumming may facilitate multiple benefits for people, it can simultaneously involve ethical breaches such as individualising practices, and culturally unsafe practices such as cultural appropriation. Specifically in this research, critical (modern and poststructural) theories were used to raise ethical questions about the adoption of cultural practices in social work, particularly in relation to: 1) the potential for ongoing cultural oppression of the group subjected to the practice; 2) the potential for cultural appropriation or cultural exploitation from the group within which the practice originated; and 3) the imposition of strategies (including alternative therapies, such as group drumming) that emphasise individualised change, rather than transformation of oppressive social 
structures. The central research questions of this study are:

- How might social work incorporate alternative practices such as group drumming in more critical ways?

- How might critical reflection enable social workers who seek to incorporate alternative practices, such as group drumming into their practice, to do this in ways that respect cultural humility and the espoused social justice and emancipatory change values of the profession?

\section{Critical reflection as a research methodology}

Critical reflection is probably more widely known as an educational tool than a research methodology. However, in both applications it enables practitioners to identify and change implicit assumptions unhelpful for espoused/intended practice (Fook, 2016). Critical reflection challenges dominant ways of knowing and seeks to uncover new perspectives. It is grounded in the critical theory traditions outlined above (drawing on both modernist and poststructural appropriations of critical theory) (Fook, 2016), and uncovers how dominant discourses and structures reinforce oppressive practices through our actions, and highlights alternatives (Morley, 2008). In revealing how we contribute to the maintenance of the current social and power relations, critical reflection can create the "conceptual space" (Rossiter, 2005) to acknowledge this and consider emancipation from it (Fook, 1993; Rossiter, 2005).

Within critically reflective research, a critical incident from practice is documented to record the key challenges posed to the practitioner. A critical incident may present as an ethical dilemma, an unsettling or troubling incident, something that is a struggle to theorise, an incident involving a challenge to link theory and practice, or an incident considered to have been executed particularly well (Fook, 2016). In this study, the researcher chose the critical incident because it represented all of these facets.

Using critical reflection as a methodology, the incident is then analysed using Fook's (2016) structured model of deconstruction and reconstruction. Deconstruction is the process of identifying and questioning the dominant discourses, values, assumptions, binary opposites, and the use of language in the research participant's account of a critical incident. This deconstructive analysis aims to reveal biases, contradictions, missing voices and alternative interpretations of the critical incident (Fook, 2016; Morley, 2008, 2014; Rossiter, 2005).

Having deconstructed the critical incident to unearth alternative interpretations, reconstruction is the next and final stage of the critical reflection research process. Reconstruction involves making new meanings of the incident with the intention of creating new knowledge that enables critical practice. This process is informed by the values of modernist critical theories, with the assistance of a poststructural lens that highlights multiple realities. This theoretical combination enables the creation of new understandings and practices that can, as in the case of this article, inform the development of critical practices that are ethical and culturally safe (Fook, 2016; Morley, 2008; Rossiter, 2005).

Critical reflection can be undertaken alone or within a group. In this study, Author 1 (Canice) worked closely with Author 2 (Christine) to critically reflect on the critical incident. The incident was also presented to a group of 15 social work student peers who acted as peer supervisors to assist the researcher to deconstruct and reconstruct the incident: thus helping to uncover hidden assumptions and generate differing perspectives that led to the development of more critical practice.

The concept of critical reflection as a process and a research methodology is contested 
(Hargreaves, 2004; Ixer, 1999, 2016; Wilson, 2013; Yip, 2006). Some of the criticisms relate primarily to the subjectivity of personal reflection given it is largely an internal, cognitive process (Hargreaves, 2004; Ixer, 1999, 2016). However, as Allen (2013, p. 154) explains, "The process is concerned with the 'story' of what happened and the contributing factors in the storying and meaning-making process, rather than finding the 'truth' or evaluating the situation or the people involved." Wilson (2013) and Ixer (2016) question the benefit and effectiveness of critical reflection and posit that the usefulness of simply taking time out to reflect so as to create new theory and practice is limited. However, this understanding of reflection misunderstands the process outlined by Fook (2016) which provides a rigorous process of theorising a practice incident, (based on critical postmodernism), involving systematic deconstruction and reconstruction.

Yip (2006) and Ixer (2016) rightly point to concerns about critical reflection in a neoliberal service delivery environment, particularly the individual nature of reflection. However, the critical element of critical reflection links directly with the political, and often uses a collective process (as was adopted in the present study) to uncover hidden assumptions and generate multiples perspectives that lead to the development of more critical practices.

\section{The critical incident}

An extract from Canice's narration of the critical incident which, in the context of critically reflection research, becomes the raw data to be analysed, follows:

When studying in Ireland I volunteered with a homework club run by a not-forprofit organisation for Traveller children, aged 8 to 12 years. The purpose was to help children whose parents could not read or write to complete their school homework tasks. The six children who regularly attended were often full of energy after sitting in school all day. Getting them to focus was challenging. One idea I had was to start our two hours together with a group drumming activity. This was based on my experience of African drumming using djembe drums. I was also aware of some research suggesting the benefits of group drumming and enjoyed drumming as personal recreation. I thought this could help the children to focus while being fun and active. Myself and the other volunteers decided to try this. At first, the children were challenging to manage in the group drumming activity, often not following instruction. Over time they became used to the routine and it was observed that they appeared better able to concentrate on their homework following the group drumming sessions. The other volunteers and I thought we had done something good for the children. We wanted to understand this more, and so I embarked on the process of subjecting this practice to critical reflection.

\section{Deconstruction of the critical incident}

Deconstruction often exposes gaps between theory and praxis (Fook, 2016). In deconstructing my practice, this manifested in multifarious ways. My practice framework derives from critical postmodern theories, and I seek to implement these into my practice in anti-oppressive and empowering ways. However, a recurring theme within my account of the incident, for example, was the need to establish and maintain control of the group with a view to achieving the group's aims - as I had defined them. Within this "expert" role, I decided group drumming, based on a style originating in West Africa, is what the children needed. This thought (or lack of thought) process had several implications for my practice:

1) It resulted in the implementation of group drumming that seems to re-enact dominant discourses in its recreation of colonial power relations. 
2) In positioning myself as the locus of control, I unwittingly created a situation where, in trying to connect the multiple players (including myself and the other volunteers, Traveller children, Traveller parents, the organisation we volunteered for and the voiceless cultures of West Africa from which group djembe drumming originated), a distance was created.

3) I had unconsciously assumed the solutions reside within people in roles of structural power (i.e., myself and my fellow volunteers), which negated the possibilities from elsewhere for achieving group aims, including through engagement with Traveller culture. This assumption also reveals modernist notions of power (i.e., that those with access to material and symbolic power according to Western social structures are ultimately the most powerful (Fook, 2016; Foucault, 1988). The construction of me as expert with the solution for group success also reproduces dominant discourses that reinforce my own privilege as a white male.

4) In occupying the role of expert, I rendered the Traveller children and their families as voiceless and powerless, and in need of my "help". This represents the paternalism embedded in my assumptions about helping. I also unintentionally maintained the dominant discourse around Travellers as a problematic part of Irish society (Allen \& Adams, 2013; Fetzer, 2017; Mulcahy, 2012), perpetuating a construction of Traveller as other and thereby continuing perceptions of them as an isolated group (Allen \& Adams, 2013; Fetzer, 2017; Mulcahy, 2012). I did not consider the multiple and contrasting Traveller identities and experiences prevalent within Ireland (Royall, 2010) and could have done so, for example, when the organisation told me the Traveller children's parents could not read or write. The result was a deficits-focused practice, which neglected meaningful engagement with Traveller culture to find solutions.

All of these realisations contradict my espoused theoretical position to recognise and value the wisdom of the people with whom I work, decentre my power as a facilitator to develop egalitarian ways of working with people, challenge colonialist practices and discourses, and create empowering and inclusive environments. This deconstruction of my practice brought to my consciousness my lack of consideration for the cultural appropriateness of implementing this group drumming activity (Bohlmann, 2003; Frith, 2003). Nor did I consider my potential appropriation of a deeply symbolic cultural activity from West Africa and the impact positioning the activity out of its cultural context may have on its effectiveness (Bannister, Soloman, \& Brunk, 2009). My intervention existed within a context and the intervention was not just a technique; there are social, ethical and moral implications in adopting practice from cultures outside of our own (Banks, 2016).

Reflecting on the incident, I see myself enacting white oppression on multiple fronts. This arises from the assumption that the children need to engage in formal education for their own benefit. This exposes hegemonic assumptions that education is beneficial to their lives (Cox, 1987; Gramsci, 1971; Laclau \& Mouffe, 1985). This seems to imply a need to fix their lives (Cox, 1987; Gramsci, 1971; Laclau \& Mouffe, 1985). I may have actually risked alienating the Traveller children further by adopting group drumming rather than engaging with values, experiences, expectations and solutions from within their culture. This perspective is silenced, as is any potential perspective of cultures from which djembe drumming originates. I did not intend to reinforce colonial power relations between Europe and Africa, nor create further sources of oppression for Traveller people in Ireland. However, in making assumptions based on 
my perspective and life experience, I have potentially recreated and reinforced these social realities.

Deconstruction of my practice raises awareness about the potential to reinforce dominant discourses and structural oppression. This emphasises the need for social workers to critically reflect on the adopting of alternative practices to ensure the aims, ethics and values of social work are upheld.

\section{Reconstructing of the critical incident and implications for practice}

Reconstruction considers new interpretations uncovered by the deconstruction process and devises ways to align espoused intentions and actual practice (Fook, 2016). Accepting that Traveller culture had its own solutions to the homework group's challenges leads me to consider other ways of engaging with Traveller children that subvert the ongoing power imbalances and cultural oppression they experience (Fetzer, 2017; Mulcahy, 2012). My reconstructed practice explicitly values the participation of Traveller people in the construction of problems and solutions. I will involve them in discussions about how we work together, rather than making unilateral decisions from the position of outside expert. This culturally safe practice (Fisher-Borne, Cain, \& Martin, 2015; Happell, Cowin, Roper, Lakeman, \& Cox, 2013) corresponds closely with my espoused ethics to work as a critical practitioner who employs antioppressive strategies to challenge dominant power relations and structures (Healy, 2014; Morley, 2008). My reconstruction of practice is concerned with the use of group drumming in a more ethical and culturally sensitive manner, rather than the abolition of it from my practice altogether.

\section{Towards ethical use of alternative practices: Shared cultural exchange}

Key learning from this reflection illuminates some broad principles for those seeking to incorporate alternative practices into their social work practice in a thoughtful, ethical and culturally safe manner.

A primary consideration begins with a critical recognition of self, particularly in relation to privilege and how standpoint enables inadvertent harms. Within Canice's own reflection, this meant acknowledging his positioning as a white male with access to multiple privileges and resources was fundamental (Pease, 2010; United Nations, 2013; Zufferey, 2013). While retaining a critical analysis of positionality and identity, its meaning for power relations and the potential for domination and exploitation, the poststructural influence within this research also emphasises the importance of context. In response to the research question, we therefore tentatively suggest not all replication of practices outside our own cultures is necessarily harmful, and we may need new terms or phrases to differentiate between cultural appropriation and what we tentatively term "shared cultural exchange", to distinguish this as a critically reflective process to benefit social workers and the cultures in question.

Cultural exchange also demands the identification of the practitioner's own position in relation to the originating culture and the seeking of permission to use the practice. This is closely followed by the need to seek genuine engagement with the originating culture to avoid re-enactment of colonial and postcolonial power relations (Bannister et al., 2009). If permitted by the individuals who hold the cultural knowledge, it is important for social workers to recognise and value the opportunity to learn about the cultural significance and practical elements of the practice. It is also an opportunity for dialogue acknowledging past wrongs, to gain consent for the use of the alternative practice and to re-negotiate power relations in a genuinely empowering and equitable way (Fook, 2016).

This reconstruction of practice is based on respect and discussion. It may involve opening a discourse with a culture wherein the practitioner's own ancestral connections 
are complicit in colonisation, exploitation and oppression (El-Lahib, 2017; Kang, 2013; Pease, 2010). Through acknowledging the predominant constructions of power in postcolonial contexts, a respectful discussion and interaction can create space where common and differing values are identified and shared cultural exchange occurs. It also creates space for social justice; enabling social workers, Travellers and Africans synthesised research, discourse and action to tackle the various forms of social, cultural and personal oppression they experience (Burns Coleman, Coombe, \& MacArailt, 2009; Healy, 2014). This is not to suggest the experience of Travellers, Africans and social workers is the same or the process of shared cultural exchange is unproblematic. Rather, a transversal perspective is important here as it recognises the different experiences of positioning in global society and values these experiences and knowledge as part of the movement towards a more equitable world (Mohanty, 2003; Yuval-Davis, 2006). Further, acknowledging cultural significance and practising ethically represents an act of resistance to globalised neoliberal capitalism by refusing to reduce cultural forms to pieces of tradable information (Burns Coleman et al., 2009; Dominelli, 2010; Fook, 2016).

Shared cultural exchange avoids the primary identifiers of inappropriate cultural appropriation. Primary among these is adopting the practice without knowledge or acknowledgement of its cultural significance. Further, lack of exposure and consent leading to caricature of a culture rather than accurate representation, followed by claims of ownership over the version of the appropriated culture when mixed with the culture of the practitioner (Bannister et al., 2009).

Finally, this critical reflection raises broader questions about the implementation of a range of alternative practices in social work. Given the growing interest in practices such as yoga (Behrman \& Tebb, 2009; Mahaffey, 2016), mindfulness and meditation (Bo et al., 2016; Garland, 2013; Winters \& Beerbower, 2017), equine therapy (Acri et al., 2016; Burgon et al., 2017) and group drumming (Bittman et al., 2001; Fancourt et al., 2016; Faulkner et al., 2012; Ho et al., 2011), the lessons from this research suggest ethical practice requires workers to consider a shared cultural exchange when adopting these practices. A shared cultural exchange requires critical reflection on the social and cultural context, the cultural norms of the group they are working with and the group they are adopting practice from, their position in relation to those groups, and the historical and contemporary power relations between the group and the social worker's background.

\section{Conclusion}

This article offers a critically reflective discussion about the use of alternative practices in social work. We used a practice incident from one of the authors to analyse a specific case example of using group drumming originating in West African with a group of Traveller children in Ireland. While the literature on group drumming is dominated by individualised and psychologised perspectives, it consistently reports positive impacts of group drumming with various population groups. Critical perspectives highlight the ethical complexities for social workers who wish to incorporate alternative practices, considering the legacy of colonialism and ongoing social injustice, oppression and exploitation within societies and across cultures. Despite laudable intentions, social workers can be implicated in the inappropriate practices of cultural appropriation as part of ongoing, unequal, postcolonial power relations.

This article provides a critical engagement with these issues, with a view to creating shared cultural exchange. It demonstrates that critical reflection is a useful tool in reconstructing practice and presents several practice principles to promote shared cultural exchange and avoid culturally unsafe practices including cultural appropriation. It therefore holds implications for social workers interested 
in the potential of alternative practices while remaining committed to critical practice and cultural safety.

\section{References}

Acri, M., Hoagwood, K., Morrissey, M., \& Zhang, S. (2016). Equine-assisted activities and therapies: Enhancing the social worker's armamentarium. Social Work Education, 35(5). doi:10.1080/02615479.2016.1173669

Allen, D., \& Adams, P. (2013). Social work with Gypsy, Roma and Traveller children. London, UK: British Association for Adoption and Fostering.

Allen, J. (2013). Using critical reflection to research spirituality in clinical practice. In J. Fook \& F. Gardner (Eds.), Critical reflection in context: Applications in health and social care (pp. 154-165). London, UK: Routledge.

Aotearoa New Zealand Association of Social Workers (ANZASW). (2007). Code of ethics, Retrieved from https://anzasw.nz/wp-content/uploads/Code-of-Ethics.pdf

Australian Association of Social Workers (AASW). (2010). Code of ethics. Retrieved from http://www.aasw.asn.au/ document/item/1201

Banks, S. (2016). Everyday ethics in professional life: Social work as ethics work. Ethics and Social Welfare, 10(1), 35-52. doi:10.1080/17496535.2015.1126623

Bannister, K., Solomon, M., \& Brunk, C. (2009). Appropriation of traditional knowledge: Ethics in the context of ethnobiology. In J. Young \& C. Brunk (Eds.), The ethics of cultural appropriation (pp. 173-210). Chichester, UK: Blackwell.

Behrman, G., \& Tebb, S. (2009). The use of complementary and alternative interventions as a holistic approach with older adults. Journal of Religion \& Spirituality in Social Work: Social Thought, 28(1-2), 127-140. doi:10.1080/15426430802644156

Bittman, B. B., Berk, L. S., Felten, D. L., Westengard, J., Simonton, C., Pappas, J., \& Ninehouser, M. (2001). Composite effects of group of drumming music therapy on modulation of neuroendocrine-immune parameters in normal parameters in normal subjects. Alternative Therapeutic Health Medicine, 7, 38-47.

Bittman, B. B., Snyder, S., Bruhn, K. T., Liebfried, F., Stevens, C., Westengard, J., \& Umbach, P. O. (2004). Recreation music making: An integrative group intervention for reducing burnout and improving mood states in first year associate degree nursing students. International Journal of Nursing Education Scholarship, 1(1), 1-12.

Bittman, B. B., Snyder, S., Bruhn, K. T., Stevens, C., Westengard, J., \& Umbach, P. O. (2003). Recreational music-making: A cost effective group interdisciplinary strategy for reducing burnout and improving mood states in long term workers. Advances in Mind-Body Medicine, 19(3/4), 4-15.

Bo, A., Mao, W., \& Lindsey, M. A. (2016). Effects of mindbody interventions on depressive symptoms among older Chinese adults: A systematic review and metaanalysis. International Journal of Geriatric Psychiatry, 32(5), 509-521. doi:10.1002/gps.4688

BohIman, P. (2003). Music and culture. In M. Clayton, T. Herbert, \& R. Middleton (Eds.), The cultural study of music: A critical introduction (pp. 45-56). London, UK: Routledge.
Branscombe, A., Chandler, P., \& Little, S. (2016). Students drum life stories: The role of cultural universals in project work. The Journal of Social Studies Research, 41(1), 53-62. doi:10.1016/j.jssr.2015.10.004

Burgon, H., Gammage, D., \& Hebden, J. (2017). Hoofbeats and heartbeats: Equine-assisted therapy and learning with young people with psychosocial issues - theory and practice. Journal of Social Work Practice, 1-15. doi:10.1080/02650533.2017.1300878

Burns Coleman, E., Coombe, R., \& MacArailt, F. (2009). A broken record: subjecting "music" to cultural rights. In J. Young \& C. Brunk (Eds.), The ethics of cultural appropriation (pp. 173-210). Chichester, UK: Blackwell.

Central Statistics Office. (2012). Statistical yearbook of Ireland 2012 edition. Retrieved from https://www. cso.ie/en/statistics/statisticalyearbookofireland/ statisticalyearbookofireland2012edition/

Charry, E. (1996). A guide to the jembe. Percussive Notes, $34(2), 66-72$.

Chenoweth, L., \& McAuliffe, D. (2015). The road to social work and human service practice (4th ed.). Melbourne, VIC: Cengage Learning.

Cox, R. (1987). Production, power and world order: Social forces in the making of history. New York, NY: Columbia University Press.

Dominelli, L. (2010). Globalisation, contemporary challenges and social work practice. International Social Work, 53(5), 599-612.

El-Lahib, Y. (2017). Theoretical dimensions for interrogating the intersection of disability, immigration and social work. International Social Work, 60(3), 640-653. doi:10.1177/0020872816651704

Fancourt, D., Perkins, R., Ascenso, S., Carvalho, L., Steptoe, A., \& Williamon, A. (2016). Effects of group drumming interventions on anxiety, depression, social resilience and inflammatory immune response among mental health service users. PLOS ONE, 11(3), e0151136. doi:10.1371/journal.pone. 0151136

Faulkner, S., Wood, L., Ivery, P., \& Donovan, R. (2012). It is not just music and rhythm: Evaluation of a drummingbased intervention to improve the social wellbeing of alienated youth. Children Australia, 37(1), 31-39. doi:10.1017/cha.2012.5

Fetzer, J. (2017). Opposition to Irish travellers' halting sites in the republic of Ireland: Realistic group conflict or symbolic politics? Irish Journal of Sociology, 25(2), 195-206. doi:10.1177/0791603516676097

Flaig, V. (2010). The politics of representation and transmission in the globalization of Guinea's djembé (Unpublished doctoral dissertation), University of Michigan, MI. Retrieved from https://deepblue.lib.umich. edu/bitstream/handle/2027.42/75801/vhflaig_1.pdf; sequence $=1$

Fook, J. (1993). Radical casework: A theory of practice. St Leonards, NSW: Allen \& Unwin.

Fook, J. (2016). Social work: A critical approach to practice. London, UK: Sage.

Fisher-Borne, M., Cain, J., \& Martin, S. (2014). From mastery to accountability: Cultural humility as an alternative to cultural competence. Social Work Education, 34(2), 165-181. doi:10.1080/02615479.20 14.977244 
Foucault, M. (1988). Politics philosophy culture. Interviews and other writings 1977-1984 (L. Kritzman, Ed.) New York, NY: Routledge.

Frankland, R., Bamblett, M., \& Lewis, P. (2011). "Forever business": A framework for maintaining and restoring cultural safety in Aboriginal Victoria. Indigenous Law Bulletin, 17(24), 27-30. Retrieved from http://www.austlii. edu.au/au/journals/ILB/2011/25.pdf

Friedman, R. (2000). The healing power of the drum: $A$ psychotherapist explores the power of rhythm. Reno, NE: White Cliffs.

Frith, S. (2003). Music and everyday life. In M. Clayton, T. Herbert, \& R. Middleton (Eds.), The cultural study of music: A critical introduction (pp. 92-101). London, UK: Routledge.

Garland, E. L. (2013). Mindfulness research in social work: Conceptual and methodological recommendations. Social Work Research, 37(4), 439-448. doi:10.1093/swr/ svt038

Gmelch, S., \& Gmelch, G. (2014). Irish travellers: The unsettled life. Bloomington, IN: Indiana University Press.

Gramsci, A. (1971). Selections from the Prison Notebooks. New York, NY: International Publishers.

Happell, B., Cowin, L., Roper, C., Lakeman, R., \& Cox, L. (2013). Introducing mental health nursing: A service user-oriented approach (2nd ed.). Sydney, NSW: Allen \& Unwin

Hargreaves, J. (2004). So how do you feel about that? Assessing reflective practice. Nurse Education Today, 24, 196-201.

Healy, K. (2014). Social work theories in context: Creating frameworks for practice (2nd ed.). London, UK: Palgrave MacMillan.

Ho, P., Tsao, J. C., Bloch, L., \& Zeltzer, L. K. (2011). The impact of group drumming on social-emotional behaviour in low-income children. Evidence-Based Complementary and Alternative Medicine, 1-17. doi:10.1093/ecam/ neq072

Ixer, G. (1999). There is no such thing as reflection. British Journal of Social Work, 29, 513-527.

Ixer, G. (2016). The concept of reflection: Is it skills-based or values? Social Work Education, 35(7), 809-824. doi:10.1080/02615479.2016.1193136

Laclau, E., \& Mouffe, C. (1985). Hegemony and socialist strategy: Towards a radical democratic politics. London, UK: Verso.

Longhofer, J., \& Floresch, J. (1993). African drumming and psychiatric rehabilitation. Psychosocial Rehabilitation Journal, 16, 3-11.

Kang, H. (2013). Claiming immigrant cultural citizenship: Applying postcolonial theories to work practice with immigrants. Critical and Radical Social Work, 1(2), 233-245.

Mahaffey, M. (2016). A yoga program as a complementary and alternative intervention for adults experiencing symptoms of grief: A grant proposal. ProQuest Dissertations Publishing. Retrieved from https://pqdtopen.proquest.com/pubnum/10127029.html

MacMillan, T., Maschi, T., \& Tseng, Y. (2012). Measuring perceived well-being after recreational drumming: An exploratory factor analysis. Families in Society: The
Journal of Contemporary Social Services, 93(1), 74-79. doi:10.1606/1044-3894.4180

Macintosh, H. (2003). Sounds of healing: Music in group work with survivors of sexual abuse. The Arts in Psychotherapy, 30, 17-23. doi:10.1016/S01974556(02)00229-0

Mohanty, C. (2003). Feminism without borders: Decolonizing theory, practicing solidarity. Durham, NC: Duke University Press.

Morley, C. (2008). Developing critical reflection as a research methodology. In P. Liamputtong, \& J. Rumbold (Eds.), Knowing differently: An introduction to experiential and arts-based research methods (pp. 265-280). New York, NY: Nova Science.

Morley, C. (2014). Practising critical reflection to develop emancipatory change. Ashgate, UK: Farnham.

Mulcahy, A. (2012). "Alright in their own place": Policing and the spatial regulation of Irish Travellers. Criminology \& Criminal Justice, 12(3), 307-327. doi: $10.1177 / 1748895811431849$

Mullaly, B. (2007). The new structural social work (3rd ed.). Toronto, ONT: Oxford University Press.

Newman, G., Maggott, C., \& Alexander, D. G. (2015). Group drumming as a burnout prevention initiative among staf members at a child and adolescent mental health care facility. South African Journal of Psychology, 45(4), 439-451. doi:10.1177/0081246315581346

Ó hAodha, M. (2011). Insubordinate Irish: Travellers in the text. Manchester, UK: Manchester University Press.

Payne, M. (2014). Modern social work theory (4th ed.). London, UK: Palgrave Macmillan.

Pease, B. (2010). Undoing privilege: Unearned advantage in a divided world. New York, NY: Zed Books.

Perkins, R., Ascenso, S., Atkins, L., Fancourt, D., \& Williamon, A. (2016). Making music for mental health: How group drumming mediates recovery. Psychology of Well-Being, 6(1). doi:10.1186/s13612-016-0048-0

Polak, R. (2005). A musical instrument travels around the world: Jembe playing in Bamako, West Africa, and beyond. In J. Post (Ed.), Ethnomusicology: A contemporary reader (pp. 161-185). New York, NY: Routledge.

Ramsden, I. M. (2002). Cultural safety and nursing education in Aotearoa and Te Waipounamu (Unpublished doctoral dissertation). Victoria University of Wellington, New Zealand. Retrieved from https://www.nzno.org.nz/ Portals/0/Files/Documents/Services/Library/2002\%20 RAMSDEN\%201\%20Cultural\%20Safety_Full.pdf

Rossiter, A. (2005). Where in the world are we? Notes on the need for a social work response to global power. In S. Hick, J. Fook, \& R. Pozzuto (Eds.), Social work: A critical turn (pp. 189-202). Toronto, ONT: Thompson Educational Publishers.

Royall, F. (2010). Opportunities and perception in proTraveller mobilisations in Ireland (1960-2000). Journal of Contemporary European Studies, 18(2), 253-269. https://doi.org/10.1080/14782804.2010.486982

Skewes McFerran, K. (2017). Which drums should we play? Social Work with Groups, 40 (1-2), 41-47. doi:10.1080/01609513.2015.1065383

United Nations Department of Economic and Social Affairs. (2013). Inequality matters: Report on the world social 
situation 2013. New York, NY: United Nations. Retrieved from www.un.org/en/development/desa/publications/ world-social-situation-2013.html

Watson, D. (2002). Drumming and improvisation with adult male sexual offenders. Music Therapy Perspectives, 20, 105-111.

Wilson, G. (2013). Evidencing reflective practice in social work education: Theoretical uncertainties and practical challenges. British Journal of Social Work, 43, 154-172.

Winkelman, M. (2003). Complementary therapy for addiction: Drumming out drugs. American Journal of Public Health, 93, 647-651. doi:10.2105/AJPH.93.4.6347

Winters, D. E., \& Beerbower, E. (2017). Mindfulness and meditation as an adjunctive treatment for adolescents involved in the juvenile justice system: Is repairing the brain and nervous system possible? Social Work in Health Care, 56(7), 615-635. doi:10.1080/00981389.20 17.1316341

Wood, L., Ivery, P., Donovan, R., \& Lambin, E. (2013). "To the beat of a different drum": Improving the social and mental wellbeing of at-risk young people through drumming. Journal of Public Mental Health, 12(2), 70-79.

Yip, K. (2006). Self-reflection in reflective practice: A note of caution. British Journal of Social Work, 36, 777-788.

Young, S. (2004). Social work theory and practice: The invisibility of whiteness. In P. Moreton-Robinson (Ed.), Whitening race: Essays in social and cultural criticism (pp. 104-118). Canberra, ACT: Aboriginal Studies Press.

Yuval-Davis, N. (2006). Human/women's rights and feminist transversal politics. In M. Marx (Ed.), Global feminism: Transnational women's activism, organizing, and human rights (pp. 275-295). New York, NY: NYU Press.

Zufferey, C. (2013). Not knowing that I do not know and not wanting to know: Reflections of a white Australian social worker. International Social Work, 56(5), 659-673. doi:10.1177/0020872812436624 